\title{
The Effects of Serendipita indica and Guanidine-Modified Nanomaterial on Growth and Development of Cabbage Seedlings and Black Spot Infestation
}

\author{
Sana Saleem ${ }^{1, *}$, Zuzana Bytešníková ${ }^{2} \mathbb{D}$, Lukáš Richtera ${ }^{2,3}{ }^{(D)}$ and Robert Pokluda ${ }^{1}$ \\ 1 Department of Vegetable Sciences and Floriculture, Faculty of Horticulture, Mendel University in Brno, \\ Valticka 337, 69144 Lednice, Czech Republic; pokluda@mendelu.cz \\ 2 Department of Chemistry and Biochemistry, Mendel University in Brno, Zemědělská 1, \\ 61300 Brno, Czech Republic; zuzana.bytesnikova@mendelu.cz (Z.B.); lukas.richtera@mendelu.cz (L.R.) \\ 3 Central European Institute of Technology, Brno University of Technology, Purkyňova 123, \\ 61200 Brno, Czech Republic \\ * Correspondence: xsaleem@mendelu.cz
}

Citation: Saleem, S.; Bytešníková, Z.; Richtera, L.; Pokluda, R. The Effects of Serendipita indica and

Guanidine-Modified Nanomaterial on Growth and Development of Cabbage Seedlings and Black Spot Infestation. Agriculture 2021, 11, 1295. https://doi.org/10.3390/ agriculture11121295

Academic Editor: Riccardo Testa, Giuseppina Migliore, Giorgio Schifani and József Tóth

Received: 25 October 2021

Accepted: 7 December 2021

Published: 19 December 2021

Publisher's Note: MDPI stays neutral with regard to jurisdictional claims in published maps and institutional affiliations.

Copyright: (c) 2021 by the authors. Licensee MDPI, Basel, Switzerland. This article is an open access article distributed under the terms and conditions of the Creative Commons Attribution (CC BY) license (https:// creativecommons.org/licenses/by/ $4.0 /)$.

\begin{abstract}
To ensure sustainable agricultural production and protection of crops from various biotic and abiotic stresses, while keeping in view environmental protection, by minimal usage of chemicals, the exploitation of beneficial microorganisms and modern nanotechnologies in the field of agriculture is of paramount importance. This study aimed to investigate the effects of Serendipita indica and guanidine-modified nanomaterial on the growth, and other selected parameters, of cabbage, as well as incidence of black spot disease. S. indica was applied in substrate and by seed inoculation. S. indica had a positive impact on the development of plants, and resulted in reduced black spot severity. The maximum plant height $(119 \mathrm{~mm})$ and number of leaves (8.3) were observed in S. indica-treated plants. Pigments were enhanced, i.e., chlorophyll $a(0.79 \mathrm{mg} / \mathrm{g})$, chlorophyll $b(0.22 \mathrm{mg} / \mathrm{g})$, and carotenoid content $(0.79 \mathrm{mg} / \mathrm{g})$, by substrate treatment. The highest antioxidant capacity $(9.5 \mathrm{mM} / \mathrm{L})$, chlorophyll $a$ and $b$ (1.8 and $0.6 \mathrm{mg} / \mathrm{g})$, and carotenoid content $(1.8 \mathrm{mg} / \mathrm{L})$ were reported in $S$. indica seed treatment. S. indica treatment resulted in $59 \%$ and $41 \%$ disease incidence decrease in substrate and seed treatment, respectively. Guanidine-modified nanomaterial was seen to be effective in improving plant growth and reducing disease incidence; however, it did not perform better than $S$. indica. Application of nanoparticles resulted in enhanced normalized difference vegetation index and fluorescence by increasing chlorophyll $a, b$, and carotenoid content. Nitrogen content was the highest in plants treated with nanoparticles. However, the effect of the combined application of fungus and nanoparticles was similar to that of $S$. indica alone in substrate treatment, although negative impacts were reported in the biochemical parameters of cabbage. S. indica has great potential to enhance plant growth and manage Alternaria incidence in cabbage crops.
\end{abstract}

Keywords: Brassica oleracea Capitata Group; Alternaria brassicicola; biological control; endophytic fungus; biotic stress

\section{Introduction}

Plant disease poses a major challenges in food production, resulting in loss of overall crop yield. To meet the increasing demand for food, and to obtain disease-free, attractive produce, the use of chemical fertilizers has become an integral part of agricultural practice, and has revolutionized the agricultural world, though at the same time, it has resulted in the negative exploitation of nature, thus disturbing the ecosystem. One of the most destructive diseases in crop production is black spot disease, caused by Alternaria brassicicola, which affects a broad range of host plants, especially plant species of Brassicaceae, such as Brassica oleracea, Brassica rapa, Brassica juncea, and Brassica napus, causing high yield losses [1]. This necrotrophic pathogen is managed by seed or foliar application of various fungicides, such 
as benzimidazoles, dicarboximides, carbamates, and triazoles; however, usage of these chemicals has been reported to have negative impacts on the environment, as well as on human health [2]. In addition, it has been reported that there is no resistant cultivar for this pathogen [3]. Therefore, the development of new strategies for managing black spot disease, with minimal environmental degradation and health hazards, is of great importance.

To mitigate the harmful impact of chemical fertilizers and pesticides on the ecosystem, and to develop a sustainable agricultural production system, the introduction of beneficial microorganisms in agricultural practice is a valuable and eco-friendly tool [4]. These microorganisms are known to overcome various plant stresses and enhance plant nutrient uptake [5]. Application of beneficial fungi to plants has resulted in increased chlorophyll content, biomass, and plant growth by enhancing photosynthetic rate and improving the availability and uptake of nutrients [6]. One of these beneficial microorganisms, Serendipita indica, is known to promote plant growth and stimulate nutrient uptake, as well as suppress various plant diseases [7,8]. S. indica is an endophytic fungus that colonizes the roots of diverse plant species, including agronomical, horticultural, and medicinal crops, as well as ornamental plants. It forms mycelium and pear-shaped chlamydospores, and can be grown axenically in different media. It was found in the rhizosphere of woody shrubs Prosopis juliflora and Zizyphus nummularia in the Thar Desert of Northwest India [9]. In tomato crops, $S$. indica resulted in significant increases in plant growth and leaf biomass, and reduced the incidence of disease caused by Verticillium dahliae by more than 30\% [10]. In Brassica campestris ssp. Chinensis, inoculation with $S$. indica resulted in enhanced biomass and reduced club-rot gall formation by up to $61.6 \%$ [11]. S. indica can be applied to plant species using various methods, such as seed inoculation, root dip, and soil inoculation. However, for successful colonization and positive interaction between inoculated microorganisms and plant tissues, it is necessary to ensure proper inoculation [12].

Apart from the use of beneficial microorganisms, the introduction of nanomaterial is considered to be a powerful tool in crop production. The application of nanoparticles has shown tremendous potential in improving agricultural production by increasing the efficiency of inputs, thus providing a better method of improving agricultural production and ensuring protection of the environment. Nanoparticles are receiving immense attention in agrotechnology due to their growth-promoting properties; for example, application of copper oxide nanoparticles improved crop production in lettuce [13]. Carbon-based nanoparticles, such as Fullerol (Bucky, USA), increased fruit number, fruit size, and final yield, as well as enhanced the content of cucurbitacin-B, lycopene, charantin, and inulin in the fruits of bitter melon plants [14]. Graphene oxide slowed down the release of potassium nitrate, thus minimizing leaching losses [15]. Sabir et al. [16] also reported that nanoparticles, such as nano-calcite, with nano $\mathrm{SiO}_{2}, \mathrm{MgO}$, and $\mathrm{Fe}_{2} \mathrm{O}_{3}$, improved the uptake of calcium, magnesium, and iron, as well as enhanced the intake of phosphorus, along with micronutrients zinc and manganese, in grapevines. Heavy metal pollution was also reduced by the application of nanoparticles [17]. Moreover, titanium dioxide nanoparticles reduced cadmium toxicity and enhanced yield in coriander [18]. Manjaiah et al. [19] also reported that application of nano-zeolite not only improved the germination and growth rates of plants, but also improved the availability of nutrients. Application of zinc oxide nanoparticles has been reported to increase biomass production and nitrogen assimilation in beans [20]. Some nanoparticles, such as silver nanoparticles, confer anti-pathogenic properties [21]. The application of silver nanoparticles has also resulted in an increase in carotenoid and phenolic content, as well as total antioxidant capacity in oakleaf lettuce, at a concentration of $40 \mathrm{ppm}$ [22]. Application of guanidine, which has also proved to be an efficient slow-release nitrogen fertilizer, reduces nitrogen loss and improves nitrogen nutrition [23]. However, the optimization of parameters and concentrations is essential to avoid phytotoxicity. S. indica cultivated with zinc oxide nanoparticles, called a nanoembedded fungus, could be useful for future agricultural applications [24]. However, not much is known about the combined application of nanoparticles and beneficial microbes 
on plants. Hence, supplementing microorganisms with nanoparticles could lead to the development of more efficient and eco-friendlier agrotechnology. Thus, the main aim of this experiment was to study the effects of the endophytic fungi $S$. indica on the growth and development of plants, and to investigate the effects of $S$. indica as a biocontrol agent against pathogens. We further studied the effects of nanoparticles alone, as well as the co-application of $S$. indica and nanoparticles, on the selected plants.

\section{Materials and Methods}

\subsection{Plant Growth Condition and Treatments}

The experiment was conducted at the Mendel University Faculty of Horticulture in Lednice under greenhouse conditions: a $20^{\circ} \mathrm{C}$ day temperature, $16^{\circ} \mathrm{C}$ night temperature, and $75 \%$ relative humidity under natural light conditions (13-14 h per day), without supplementation. Seeds of cabbage cultivar Betti F1 (Moravoseed, Mikulov, Czech Republic) were sown in plug trays using a sterile perlite substrate. Each plug comprised one plant serving as a replicate, and seven replicates were maintained. Before sowing, the cabbage seeds were surface sterilized with $0.5 \%$ sodium hypochlorite for $10 \mathrm{~min}$, rinsed three times with distilled water, and left to air dry. The experiment lasted nine weeks; seedlings were fertigated weekly with Solinure GT fertilizer, 18\% N, 11\% P, and 11\% K (ICL Specialty Fertilizers, Brno, Czech Republic) in $20 \mathrm{ml} / \mathrm{L}$ doses.

The multifactorial experiment design consisted of 15 treatments in three repetitions, involving substrate treatments with a single inoculation of $S$. indica $(\mathrm{Sp})$ and nanoparticles (Np1, Np2), co-inoculation of $S$. indica with nanoparticles $(\mathrm{Sp}+\mathrm{Np} 1, \mathrm{Sp}+\mathrm{Np} 2)$ and Alternaria brassicicola (Alt), and respective combinations of Alt $+\mathrm{Sp}$, Alt+Np1, and Alt+Np2. Additionally, the seed treatments that were used for $S$. indica inoculation (Ssp), nanoparticles $(\mathrm{Ssp}+\mathrm{Np} 1, \mathrm{Ssp}+\mathrm{Np} 2)$, and Alternaria brassicicola $(\mathrm{Ssp}+\mathrm{Alt})$ with S. indica inoculation were sprayed on the plant leaves. No $S$. indica was present in the phosphate-buffered saline (C-PBS)-treated inoculating solution for the substrate control. The sterile distilled water $\left(\mathrm{C}-\mathrm{H}_{2} \mathrm{O}\right)$ seed treatment control also served as the plant control.

\subsection{Serendipita indica Inoculation}

Serendipita indica strain DSM 11827 was obtained from the "Deutsche Sammlung für Mikroorganismen und Zellkulturen", Braunschweig, Germany. The fungus was maintained in sterile potato dextrose broth (PDB) and grown on potato dextrose agar (PDA) plates. A PDB culture of $S$. indica was cultivated in the dark for 15 days at $24{ }^{\circ} \mathrm{C}$ on an orbital shaker (140 rpm). The culture was filtered using filter paper. The mycelium was smashed, rinsed three times with distilled water, and centrifuged after each washing step (4000 $\times g$ for seven minutes) (Centrifuge Z326K, Hermle, Gosheim, Germany). The liquid suspension was prepared by thoroughly mixing $S$. indica with distilled water to form a $3 \%(w / v)$ concentration of inoculating solution.

A liquid suspension of $S$. indica was injected into the root zone of each plant 20 days after sowing for substrate treatment inoculation. The seeds were treated by immersion in $S$. indica suspension for $10 \mathrm{~min}$, and an $8 \mathrm{~mL}$ dose (per plant) of the remaining suspension was poured into each plug after sowing. Control plants received the same volume of distilled water. The figures for mycelia colonizing the cabbage roots were collected using a confocal microscope LSM 800 (Carl Zeiss, Jena, Germany).

\subsection{Pathogen Application}

The disease management study was performed using the black spot disease-causing pathogenic fungus, Alternaria brassicicola. Plants were inoculated a week after the application of $S$. indica. The leaves were infected with a spore suspension collected from a two-week-old fungal culture of A. brassicicola. Then, $10 \mathrm{~mL}$ of C-PBS and $2 \mu \mathrm{L}$ of Silwet Star (AgroBio, Opava, Czech Republic) detergent were poured into a Petri dish (60 mm for pathogen culture), and a sterile plastic tool was used to release the culture spores. The spores were counted using a Cyrus counting chamber, and the spore concentration was 
adjusted to $1.10^{6}$ spores $/ \mathrm{mL}$. Next, $200 \mu \mathrm{L}$ of this liquid suspension was used to infect two leaves per plant. Phosphate-buffered saline was used on the control plants in place of $A$. brassicicola.

\subsection{Preparation of Nanoparticles}

Unless otherwise stated, the chemicals used for synthesis were purchased from SigmaAldrich (St. Louis, MO, USA). The chemicals were used in ACS-grade (American Chemical Society) double-distilled water with a resistivity of $18.2 \mathrm{M} \Omega \cdot \mathrm{cm}^{-1}$ (Milli-Q, Millipore System Inc., Burlington, MA, USA). The $\mathrm{pH}$ was measured using a $\mathrm{pH}$ meter from WTW inoLab (Weilheim, Germany).

According to modified Hummer's method, previously described in Richtera et al. [25], graphene oxide was synthesized from graphite flakes. In this experiment, cyano-substituted guanidine was used: $1 \mathrm{~g}$ of guanidine was dissolved in $50 \mathrm{~mL}$ of Milli-Q water and mixed with $20 \mathrm{~mL}$ of graphene oxide $(5 \mathrm{~g} / \mathrm{L})$. The mixture was sonicated for one hour and then stirred at $500 \mathrm{rpm}$ for three days. The same procedure was conducted for a second time, using $2 \mathrm{~g}$ of guanidine. We obtained the material for both mixtures from the chemistry department of Mendel University in Brno. Graphene oxide was formed as a single-layer structure of carbon and oxygen atoms in unreduced form, with a high density of oxygencontaining functional groups. Graphene foil forms with $0.5 \mathrm{~nm}$ to $10 \mu \mathrm{m}$ thickness were used for the experiment. The Np1 and Np2 nanoparticle solution was diluted 20 times, and $7 \mathrm{~mL}$ of solution was applied per plant by spraying the solution evenly over the leaves three weeks after the A. brassicicola inoculation. Distilled water was sprayed as a control.

\subsubsection{Scanning Electron Microscopy and Energy Dispersive X-ray Spectroscopy}

The sample was examined by scanning electron microscopy (SEM) using a TESCAN MAIA 3 equipped with a field emission gun (Tescan Ltd., Brno, Czech Republic, EU). The graphene oxide sample was dispersed in solution and diluted 1:200 with Milli-Q water, applied to a silicon wafer from the Siegert Wafer company, and allowed to dry at laboratory temperature $\left(20-25^{\circ} \mathrm{C}\right)$. Carbon tape adhered this wafer to the stub inserted into the SEM. The best image was taken using the In-Beam SE detector with a working distance of about $5.0 \mathrm{~mm}$ at $5 \mathrm{kV}$ acceleration voltages. Pictures were obtained at 5000-fold magnification, covering a sample area of $41.5 \mu \mathrm{m}$. Full-frame capture was performed in UH resolution mode, taking about $0.5 \mathrm{~min}$ with a $\sim 32 \mu \mathrm{s} /$ pixel dwell time. The spot size was set at $3.1 \mathrm{~nm}$. Images of samples for energy-dispersive X-ray spectroscopy (EDS) analysis were made on a TESCAN MIRA 2 SEM (Tescan Ltd., Brno, Czech Republic), using an E-T SE detector with a $15 \mathrm{kV}$ accelerating voltage. The working distance was set at about $15 \mathrm{~mm}$, and $\mathrm{UH}$ resolution mode was used for scanning. The measurement was performed at a high vacuum. Elemental analysis was made on an X-MAX 50 EDX detector (Oxford instruments plc, Abingdon, UK). Input energy was set at about 18.000-20.001 cts, and output energy was about $15.000-16.000 \mathrm{cts}$. The spot size was $70 \mathrm{~nm}$, and deadtime fluctuated between $20-27 \%$. The time taken for each analysis was $20 \mathrm{~min}$.

\subsubsection{Elemental Measurement}

All CHNS analysis measurements were performed using a FLASH 2000 organic elemental analyzer (Thermo Fisher Scientific Inc., Waltham, MA, USA). The measurement standards were purchased from Thermo Fisher Scientific Inc. For CHNS measurement, 1-3 mg of the measured sample was placed in a soft tin container and introduced into a quartz reactor filled with copper oxide and electrolytic copper. The reactor was heated to $950{ }^{\circ} \mathrm{C}$, and a small volume of oxygen was injected along with the sample. The machine's in-built detector measured the gases released by the sample's combustion.

\subsection{Morphological and Physiological Parameters}

This study's morphological and physiological parameters were the plants' height, the number of leaves, steady-state fluorescence level ( $\mathrm{Ft})$, and Normalized Difference Vege- 
tation Index (NDVI). The height of the plants was measured from the base to the longest leaf using a digital scale and expressed in $\mathrm{mm}$. The number of leaves was determined by counting each plant's true leaves. Data were collected from the seven replicates, and an average value was calculated. NDVI and Ft were measured by using a PlantPen and a FluorPen FP 110 (Photon Systems Instruments, Czech Republic), respectively. Ft was measured from 10 am to $12 \mathrm{pm}$ with no dark adaptation. The photon flux density for $\mathrm{Ft}$ observation was $3000 \mu \mathrm{mol} / \mathrm{m}^{2} / \mathrm{s}$. Data were collected from three leaves per plant.

\subsection{Biochemical Analysis}

After measuring the morphological and physiological parameters, leaves were harvested from each treatment's seven replicates and used to analyze the following biochemical parameters: chlorophyll $a$ and $b$ content, carotenoid content, total antioxidant capacity, and nitrogen content.

The chlorophyll $a, b$, and carotenoid content were determined by taking leaf samples. A dried leaf sample (0.2 g) was extracted in $100 \%$ (v/v) aqueous acetone. Absorbance was determined at wavelengths of 662,644 , and $440 \mathrm{~nm}$ for chlorophyll $a$ and $b$ and carotenoids, using a Specord 50 plus spectrophotometer (Analytik Jena, Thuringia, Germany). These absorption measurements were used to quantify the chlorophyll $a$, chlorophyll $b$, and total carotenoid content based on the Holm equation [26].

The samples' total antioxidant capacity (TAC) was determined using a modified 2,2diphenyl-1-picrylhydrazyl (DPPH) assay [27]. A $3.0 \mathrm{~g}$ leaf sample was extracted in 75\% methanol for $24 \mathrm{~h}$, followed by filtration and analyses. Absorbance was measured after $30 \mathrm{~min}$ at a $515 \mathrm{~nm}$ wavelength, using a Specord 50 plus spectrophotometer (Analytik Jena, Thuringia, Germany). The obtained data were expressed as $\mathrm{mM} / \mathrm{L}$ and used to calculate the TAC.

The plants' nitrogen content was determined using the Kjeldahl $\mathrm{H}_{2} \mathrm{SO}_{4}$ mineralization method. A sample\#x2019;s nitrogen content was calculated from the quantified amount of ammonia ions in the receiving solution [28].

\subsection{Disease Analysis}

The degree of infection on the leaves was assessed 9, 12, and 15 days after inoculation. Disease intensity in the investigated leaves was rated using a 0-5 scale: 0 -no spots and no chlorosis; 1 -symptoms on up to $10 \%$ of the area; 2 -symptoms on $11-25 \%$; 3 -symptoms on 26-50\%; 4-symptoms on 51-75\%; and 5-symptoms on more than $76 \%$ of the area. The scale was determined by calculating the mean ratings [29]. Disease incidence in the plants was determined by calculating the percentage of infection using the following formula [30]:

$$
\text { Percentage of infection }=\frac{\text { Number of infected leaves per plant }}{\text { Total number of plant leaves }} \times 100
$$

\subsection{Statistical Analysis}

The data were analyzed using STATISTICA 12 CZ software (StatSoft CR Ltd., Prague, Czech Republic). ANOVA analysis and the Fisher LSD test at probability level $p=0.05$ were carried out. In addition, Pearson correlation coefficient analyses were conducted at $p=0.05$.

\section{Results}

\subsection{Characterization of Graphene Oxide and Modified Graphene Oxide with Guanidine}

The modified Hummer's method resulted in graphene oxide sheets over a wide area. In Figure 1A, a large graphene oxide sheet measuring dozens of micrometers can be observed. The surface of the graphene oxide sheet has a distinctly smooth surface with minimum wrinkles, typical for this material. Scanning electron microscopy confirmed large pieces of guanidine successfully binding to the graphene oxide (Figure 1B,C). Elemental analysis of the graphene oxide modified with guanidine (Table 1) was used for quantitative 
evaluation for the presence of nitrogen, confirming successful guanidine modification. The presence of nitrogen was also confirmed using EDS mapping (Figure 2).

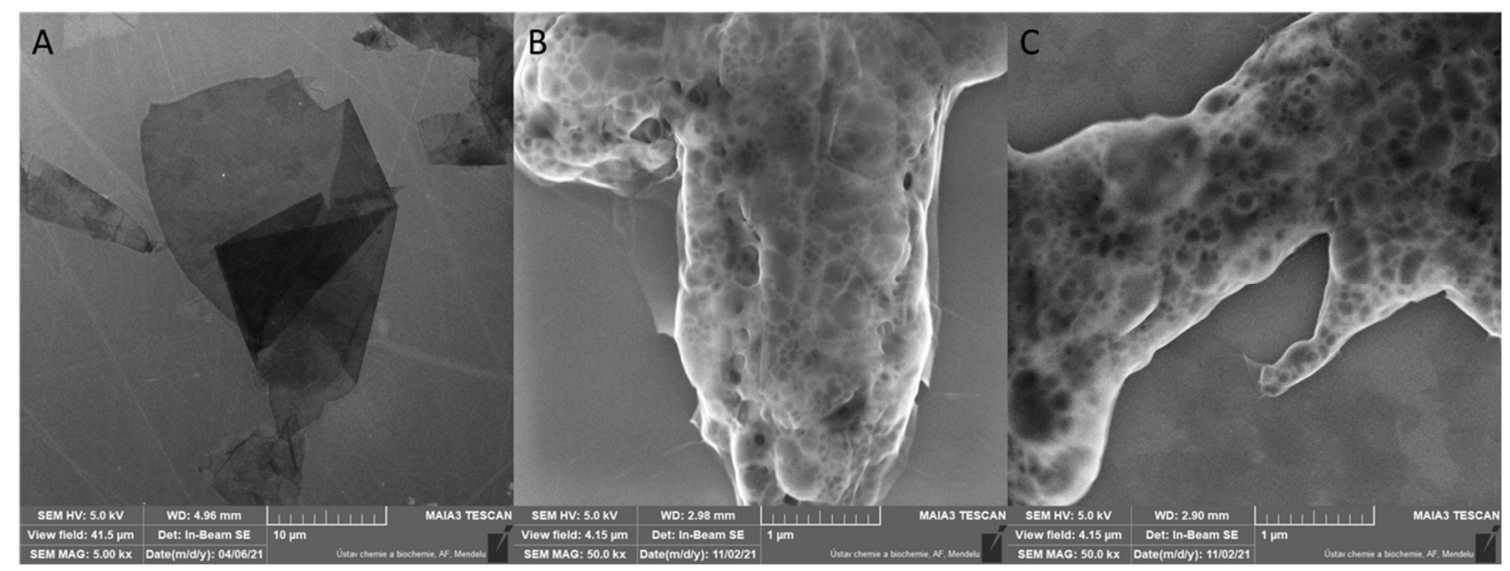

Figure 1. Scanning electron microscopy (SEM) images of graphene oxide (A) of graphene oxide-guanidine Np1 (B) and graphene oxide-guanidine $\mathrm{Np} 2(\mathrm{C})$.

Table 1. Elemental analysis of graphene oxide with guanidine confirming the high amount of nitrogen.

\begin{tabular}{ccccc}
\hline Sample & Nitrogen (\%) & Carbon (\%) & Hydrogen (\%) & Sulphur (\%) \\
\hline GO_Np1 & 57.58 & 30.07 & 4.49 & 0 \\
GO_Np2 & 60.47 & 29.58 & 4.60 & 0 \\
\hline
\end{tabular}

GO_Np_graphene oxide with guanidine nanoparticle.
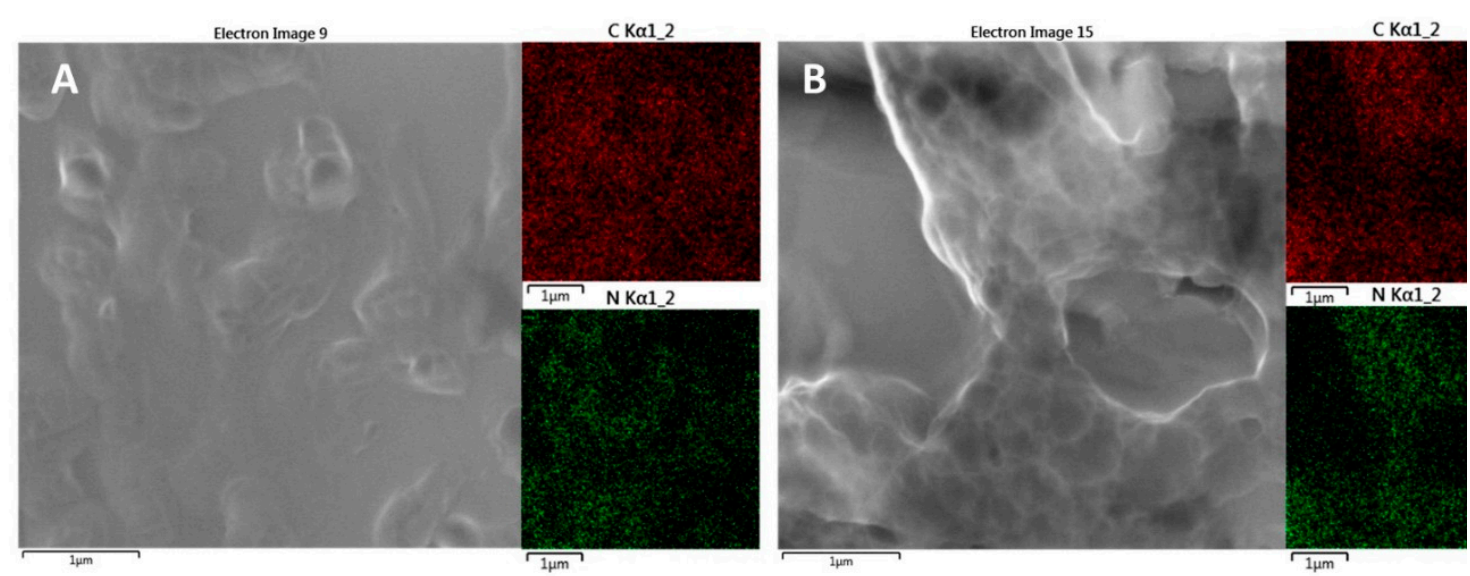

Figure 2. Energy-dispersive X-ray spectroscopy (EDS) mapping of graphene oxide-guanidine Np1 (A) and graphene oxide-guanidine $\mathrm{Np} 2$ (B) with the corresponding elemental mapping of carbon and nitrogen.

\subsection{Morphological and Physiological Parameters}

\subsubsection{Plant Height}

The plants with substrate inoculated with $S$. indica were significantly taller than the control plants, as indicated in Table 2. The mean plant height was $119 \mathrm{~mm}$ in the Sp treatment and $103 \mathrm{~mm}$ in C-PBS. Although nanoparticle application improved plant growth (Np1 $108 \mathrm{~mm}, \mathrm{~Np} 2113 \mathrm{~mm}$ ) compared to the control, the performance in combination with $\mathrm{S}$. indica showed a significant decrease in $\mathrm{Sp}+\mathrm{Np} 1(109 \mathrm{~mm})$ compared to Sp. In the seed treatment, no significant improvement was recorded compared to the control. However, in $\mathrm{Ssp}+\mathrm{Np} 2$, reduced plant height was recorded. Under disease conditions, the plants did not significantly differ in plant height. Figure 3 shows mycelia of $S$. indica colonizing roots of cabbage. 
Table 2. Effect of S. indica and guanidine-modified nanomaterial on morphology of cabbage plant.

\begin{tabular}{ccc}
\hline Treatment & Plant Height $(\mathbf{m m})$ & No. of Leaves per Plant \\
\hline C-PBS & Substrate treatment & \\
Sp & $102.75 \pm 2.39^{\mathrm{c}}$ & $6.85 \pm 0.26^{\mathrm{b}}$ \\
$\mathbf{N p 1}$ & $119.25 \pm 3.69^{\mathrm{a}}$ & $8.14 \pm 0.26^{\mathrm{a}}$ \\
$\mathbf{N p 2}$ & $108.42 \pm 2.71^{\mathrm{b}}$ & $8.14 \pm 0.26^{\mathrm{a}}$ \\
Sp+Np1 & $112.70 \pm 3.12^{\mathrm{ab}}$ & $6.71 \pm 0.28^{\mathrm{b}}$ \\
Sp+Np2 & $108.75 \pm 1.87^{\mathrm{b}}$ & $8.28 \pm 0.18^{\mathrm{a}}$ \\
& $114.90 \pm 2.21^{\mathrm{ab}}$ & $8.14 \pm 0.26^{\mathrm{a}}$ \\
\hline C-H $\mathbf{O}$ & Seed treatment & \\
Ssp & $106.85 \pm 3.19^{\mathrm{a}}$ & $5.28 \pm 0.28^{\mathrm{a}}$ \\
Ssp+Np1 & $110.45 \pm 3.33^{\mathrm{a}}$ & $5.71 \pm 0.29^{\mathrm{a}}$ \\
Ssp+Np2 & $108.21 \pm 4.87^{\mathrm{a}}$ & \\
\hline & $97.51 \pm 4.07^{\mathrm{b}}$ & \\
\hline Alt & Disease treatment & \\
\hline Alt $+\mathbf{S}$ & $107.02 \pm 3.43^{\mathrm{a}}$ & $7.14 \pm 0.26^{\mathrm{a}}$ \\
Alt+Np1 & $104.75 \pm 1.86^{\mathrm{a}}$ & $7.57 \pm 0.36^{\mathrm{a}}$ \\
Alt+Np2 & $105.80 \pm 1.32^{\mathrm{a}}$ & $7.14 \pm 0.34^{\mathrm{a}}$ \\
Ssp+Alt & $105.80 \pm 2.39^{\mathrm{a}}$ & $7.14 \pm 0.34^{\mathrm{a}}$ \\
\hline
\end{tabular}

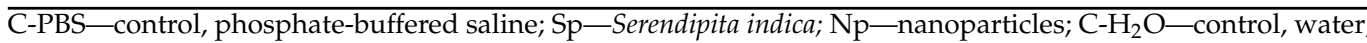
Ssp-seed application of Serendipita indica; Alt-Alternaria brassicicola. Mean values denoted by same letters does not show statistically significant difference. Means are followed by standard error data.

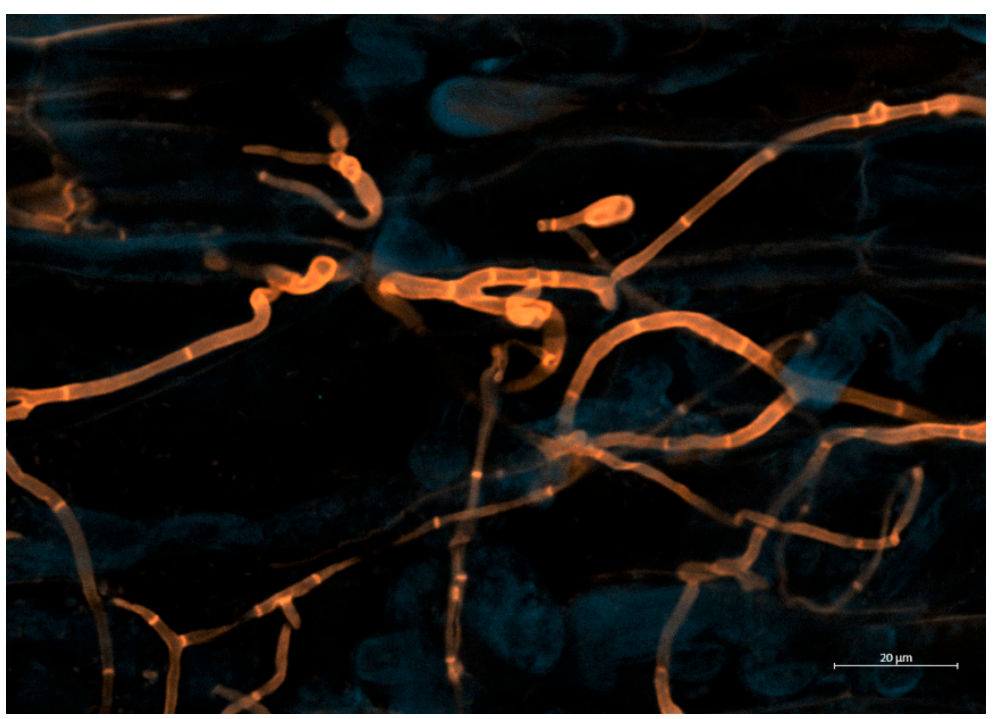

Figure 3. Mycelia of $S$. indica colonizing roots of cabbage. Bar represents $20 \mu \mathrm{m}$ scale.

\subsubsection{Number of Leaves}

Regarding substrate treatment, the mean number of leaves per plant was higher in plants treated with $S$. indica, as shown in Table 2, compared to the control (6.85). Leaf numbers were recorded as 8.28 leaves per plant in $\mathrm{Sp}+\mathrm{Np} 1$ and 8.14 leaves per plant in $\mathrm{Sp}$, $\mathrm{Sp}+\mathrm{Np} 2$, and $\mathrm{Np} 1$. However, there was no significant difference in plants inoculated with S. indica seed inoculation, recorded in the range of 5.3-5.7 leaves per plant. In addition, plants did not show any significant difference under disease conditions except the Ssp+Alt treatment, with significantly fewer leaves.

\subsubsection{Normalized Difference Vegetation Index}

The Normalized Difference Vegetation Index (NDVI) was higher in substrate-treated with S. indica than the control (C-PBS). As indicated in Table 3, the mean NDVI value in 
treated plants (Sp) was 0.67, whereas in C-PBS, it was 0.62 . However, plants treated with $\mathrm{Sp}+\mathrm{Np} 1$ and $\mathrm{Sp}+\mathrm{Np} 2$ showed higher NDVI than Sp (0.69). Seed treatment did not report any significant difference in recorded NDVI values. The NDVI of plants under disease conditions was the same as $S$. indica-inoculated plants (Alt+Sp). However, the NDVI was significantly higher in Alt+Np1, Alt+Np2, and Ssp+Alt treatments.

Table 3. Effect of S. indica and guanidine-modified nanomaterial on evaluated parameters of cabbage plants.

\begin{tabular}{|c|c|c|}
\hline Treatment & NDVI & Ft \\
\hline \multicolumn{3}{|c|}{ Substrate treatment } \\
\hline C-PBS & $0.62 \pm 0.005^{d}$ & $0.76 \pm 0.009^{d}$ \\
\hline $\mathrm{Sp}$ & $0.67 \pm 0.007^{b c}$ & $0.80 \pm 0.001^{\mathrm{a}}$ \\
\hline Np1 & $0.67 \pm 0.007^{a b c}$ & $0.78 \pm 0.005^{\mathrm{abc}}$ \\
\hline $\mathrm{Np} 2$ & $0.67 \pm 0.01 \mathrm{abc}$ & $0.78 \pm 0.005^{b c}$ \\
\hline $\mathrm{Sp}+\mathrm{Np} 1$ & $0.69 \pm 0.007^{\mathrm{ab}}$ & $0.79 \pm 0.002^{a b}$ \\
\hline $\mathrm{Sp}+\mathrm{Np} 2$ & $0.69 \pm 0.01^{\mathrm{a}}$ & $0.79 \pm 0.001^{a b}$ \\
\hline \multicolumn{3}{|c|}{ Seed treatment } \\
\hline $\mathrm{C}-\mathrm{H}_{2} \mathrm{O}$ & $0.67 \pm 0.004^{\mathrm{a}}$ & $0.77 \pm 0.003^{a}$ \\
\hline Ssp & $0.66 \pm 0.007^{a}$ & $0.77 \pm 0.001^{\mathrm{a}}$ \\
\hline$S s p+N p 1$ & $0.68 \pm 0.005^{a}$ & $0.77 \pm 0.003^{a}$ \\
\hline $\mathrm{Ssp}+\mathrm{Np} 2$ & $0.67 \pm 0.01^{\mathrm{a}}$ & $0.77 \pm 0.004^{\mathrm{a}}$ \\
\hline \multicolumn{3}{|c|}{ Disease treatment } \\
\hline Alt & $0.60 \pm 0.003^{b}$ & $0.52 \pm 0.01^{b}$ \\
\hline$A 1 t+S p$ & $0.61 \pm 0.006^{\mathrm{b}}$ & $0.63 \pm 0.03^{a}$ \\
\hline Alt+Np1 & $0.65 \pm 0.01^{\mathrm{a}}$ & $0.54 \pm 0.02^{b}$ \\
\hline $\mathrm{Alt}+\mathrm{Np} 2$ & $0.66 \pm 0.01^{\mathrm{a}}$ & $0.52 \pm 0.10^{b}$ \\
\hline Ssp+Alt & $0.66 \pm 0.01^{\mathrm{a}}$ & $0.52 \pm 0.02^{b}$ \\
\hline
\end{tabular}

\subsubsection{Chlorophyll Fluorescence}

In the substrate treatment, $S$. indica-inoculated plants recorded a significantly higher Ft level (0.8) than the control (0.76). The combined application of nanoparticles with $S$. indica also showed higher $\mathrm{Ft}$ than the control. In addition, the individual application of nanoparticles $\mathrm{Np} 1$ and $\mathrm{Np} 2$ recorded significantly higher results $(0.78)$ than the control. There was no significant difference in seed treatment. Under disease treatments, the Ft was significantly raised in Alt+Sp (0.63) and lower in Alt (0.52) (Table 3).

\subsection{Biochemical Parameters}

\subsubsection{Total Antioxidant Capacity}

Table 4 indicates that no significant difference was recorded in TAC in the substrate treatment, but it was insignificantly higher in Np1 $(7.32 \mathrm{mM} / \mathrm{L})$. However, in the case of seed treatment, $S$. indica-treated plants showed higher TAC than the control, at $9.4 \mathrm{mM} / \mathrm{L}$ in Ssp and $8.24 \mathrm{mM} / \mathrm{L}$ in $\mathrm{C}-\mathrm{H}_{2} \mathrm{O}$. The combination of $\mathrm{S}$. indica with $\mathrm{Np} 1$ and $\mathrm{Np} 2$ recorded higher TAC than the $\mathrm{C}-\mathrm{H}_{2} \mathrm{O}$ control, but was the same as Ssp. Alternaria-infected plants showed higher TAC in plants treated with $S$. indica $(\mathrm{Sp})$ in the substrate zone, recorded as $7.51 \mathrm{mM} / \mathrm{L}$, whereas in the control plants (Alt), TAC was $6.06 \mathrm{mM} / \mathrm{L}$. The results of seed treatment Ssp+Alt were not significantly different from the control. 
Table 4. Effect of $S$. indica and guanidine-modified nanomaterial on biochemical properties of cabbage.

\begin{tabular}{|c|c|c|c|c|c|}
\hline Treatments & TAC (mM/L) & $\begin{array}{c}\text { Chlorophyll } a \\
(\mathrm{mg} / \mathrm{g})\end{array}$ & $\begin{array}{c}\text { Chlorophyll } b \\
(\mathrm{mg} / \mathrm{g})\end{array}$ & $\begin{array}{c}\text { Carotenoids } \\
\text { Content (mg/g) }\end{array}$ & $\begin{array}{c}\text { Nitrogencontent } \\
(\%)\end{array}$ \\
\hline \multicolumn{6}{|c|}{ Substrate treatment } \\
\hline C-PBS & $6.90 \pm 0.45^{\mathrm{abc}}$ & $0.76 \pm 0.001^{\mathrm{d}}$ & $0.20 \pm 0.001^{\mathrm{c}}$ & $0.76 \pm 0.001^{f}$ & $1.48 \pm 0.01^{b}$ \\
\hline$S p$ & $7.07 \pm 0.16^{\mathrm{ab}}$ & $0.79 \pm 0.001^{b}$ & $0.22 \pm 0.002^{a b}$ & $0.79 \pm 0.001^{\mathrm{d}}$ & $1.48 \pm 0.01^{b}$ \\
\hline Np1 & $7.32 \pm 0.05^{\mathrm{a}}$ & $0.83 \pm 0.001^{\mathrm{a}}$ & $0.22 \pm 0.001^{b}$ & $1.57 \pm 0.001^{\mathrm{a}}$ & $1.83 \pm 0.02^{\mathrm{a}}$ \\
\hline Np2 & $7.28 \pm 0.05^{a b}$ & $0.71 \pm 0.001^{\mathrm{e}}$ & $0.19 \pm 0.001^{\mathrm{d}}$ & $1.35 \pm 0.001^{\mathrm{c}}$ & $1.86 \pm 0.01^{\mathrm{a}}$ \\
\hline$S p+N p 1$ & $6.63 \pm 0.15^{b c}$ & $0.71 \pm 0.001^{\mathrm{f}}$ & $0.19 \pm 0.001^{\mathrm{d}}$ & $1.40 \pm 0.001^{\mathrm{b}}$ & $1.48 \pm 0.01^{b}$ \\
\hline $\mathrm{Sp}+\mathrm{Np} 2$ & $7.01 \pm 0.20^{\mathrm{ab}}$ & $0.78 \pm 0.001^{\mathrm{c}}$ & $0.22 \pm 0.001^{\mathrm{a}}$ & $0.78 \pm 0.001^{\mathrm{e}}$ & $1.46 \pm 0.01^{b}$ \\
\hline \multicolumn{6}{|c|}{ Seed treatment } \\
\hline $\mathrm{C}-\mathrm{H}_{2} \mathrm{O}$ & $8.24 \pm 0.41^{b}$ & $1.75 \pm 0.001^{b}$ & $0.49 \pm 0.004^{b}$ & $1.75 \pm 0.001^{b}$ & $2.32 \pm 0.03^{a}$ \\
\hline Ssp & $9.46 \pm 0.05^{\mathrm{a}}$ & $1.78 \pm 0.001^{\mathrm{a}}$ & $0.59 \pm 0.001^{\mathrm{a}}$ & $1.78 \pm 0.001^{\mathrm{a}}$ & $2.02 \pm 0.02^{b}$ \\
\hline $\mathrm{Ssp}+\mathrm{Np} 1$ & $9.99 \pm 0.27^{\mathrm{a}}$ & $1.27 \pm 0.001^{\mathrm{d}}$ & $0.36 \pm 0.002^{d}$ & $1.40 \pm 0.001^{\mathrm{d}}$ & $2.02 \pm 0.01^{b}$ \\
\hline $\mathrm{Ssp}+\mathrm{Np} 2$ & $9.64 \pm 0.53^{\mathrm{a}}$ & $1.44 \pm 0.001^{\mathrm{c}}$ & $0.39 \pm 0.001^{\mathrm{c}}$ & $1.44 \pm 0.001^{\mathrm{c}}$ & $2.02 \pm 0.01^{b}$ \\
\hline \multicolumn{6}{|c|}{ Disease treatment } \\
\hline Alt & $6.06 \pm 0.05^{\mathrm{cd}}$ & $0.82 \pm 0.001^{\mathrm{d}}$ & $0.24 \pm 0.001^{\mathrm{d}}$ & $0.82 \pm 0.001^{\mathrm{d}}$ & $0.85 \pm 0.04^{\mathrm{d}}$ \\
\hline$A l t+S p$ & $7.51 \pm 0.30^{\mathrm{a}}$ & $0.93 \pm 0.001^{\mathrm{c}}$ & $0.26 \pm 0.003^{c}$ & $0.93 \pm 0.001^{c}$ & $1.70 \pm 0.03^{c}$ \\
\hline$A 1 t+N p 1$ & $6.85 \pm 0.21^{\mathrm{abc}}$ & $1.00 \pm 0.001^{b}$ & $0.28 \pm 0.001^{b}$ & $1.00 \pm 0.001^{b}$ & $1.85 \pm 0.01^{b}$ \\
\hline $\mathrm{Alt}+\mathrm{Np} 2$ & $7.16 \pm 0.27^{a b}$ & $0.82 \pm 0.001^{\mathrm{d}}$ & $0.23 \pm 0.001^{\mathrm{e}}$ & $0.82 \pm 0.001^{\mathrm{d}}$ & $1.75 \pm 0.02^{c}$ \\
\hline Ssp+Alt & $6.61 \pm 0.56^{\mathrm{bcd}}$ & $2.12 \pm 0.001^{\mathrm{a}}$ & $0.66 \pm 0.001^{\mathrm{a}}$ & $3.59 \pm 0.001^{\mathrm{a}}$ & $2.68 \pm 0.05^{\mathrm{a}}$ \\
\hline
\end{tabular}

C-PBS—control, phosphate-buffered saline; Sp-Serendipita indica; $\mathrm{Np}$-nanoparticles; $\mathrm{C}-\mathrm{H}_{2} \mathrm{O}$-control, water; Ssp-seed application of Serendipita indica; Alt-Alternaria brassicicola. Mean values denoted by same letters does not show statistically significant difference. Means are followed by standard error data.

\subsubsection{Chlorophyll Content}

Table 4 indicates that in substrate treatment, chlorophyll $a$ content was higher in $\mathrm{Np} 1(0.83 \mathrm{mg} / \mathrm{g})$ than the control, followed by Sp and Sp+Np2. Ssp recorded a higher chlorophyll $a$ content $(1.78 \mathrm{mg} / \mathrm{g})$ in the seed treatment than in the other treatments. In the substrate treatment, chlorophyll $b$ was higher in $\mathrm{Sp}+\mathrm{Np} 2, \mathrm{~Np} 1$, and $\mathrm{Sp}(0.22 \mathrm{mg} / \mathrm{g})$, while in the control, it was recorded as $0.20 \mathrm{mg} / \mathrm{g}$. Ssp recorded a higher chlorophyll $b$ content $(0.59 \mathrm{mg} / \mathrm{g})$ in the seed treatment than in the other treatments. However, both chlorophyll $a$ and $b$ were reduced in the seed treatment by applying Ssp+Np1 and Ssp+Np2.

In the case of disease treatment, higher chlorophyll $a(2.12 \mathrm{mg} / \mathrm{g})$ and chlorophyll $b(0.66 \mathrm{mg} / \mathrm{g})$ content were recorded in seeds treated with S. indica (Ssp+Alt) than in the control (Alt), as shown in Table 4. Chlorophyll $a$ and chlorophyll $b$ were also higher in the Alt $+\mathrm{Np} 1$ treatment, followed by Alt+Sp.

\subsubsection{Carotenoids Content}

In the substrate treatment, total carotenoid content was recorded as the highest in plants treated with $\mathrm{Np} 1(1.57 \mathrm{mg} / \mathrm{g})$ and the lowest in the control plants $(0.76 \mathrm{mg} / \mathrm{g})$, as shown in Table 4. All treatments showed higher carotenoid content when compared to the control. In Ssp, the seed treatment recorded maximum carotenoid content $(1.78 \mathrm{mg} / \mathrm{g})$. The combination of $S$. indica and nanoparticles did not report a positive effect. In the case of disease treatments, carotenoid content was higher in Ssp+Alt $(3.59 \mathrm{mg} / \mathrm{g})$ than in control (Alt) or other treatments.

\subsubsection{Nitrogen Content}

Table 4 indicates no significant effect on the nitrogen content in plants treated with Sp alone or in combination with nanoparticles in the substrate, recorded as $1.5 \%$. However, the nitrogen content was significantly higher in plants treated with nanoparticles alone at $1.83 \%$ and $1.86 \%$ in $\mathrm{Np} 1$ and $\mathrm{Np} 2$, respectively. All seed treatments recorded lower nitrogen content compared to the control seeds. Under disease conditions, Ssp+Alt reported 
higher nitrogen content $(2.68 \%)$ when compared to the Alt treatment $(0.85 \%)$. Moreover, nitrogen content was improved in $S$. indica-inoculated plants under disease conditions: $\mathrm{Alt}+\mathrm{Sp}=1.70 \%$

\subsection{Disease Incidence}

Substrate and seed colonization by $S$. indica significantly reduced the size of lesions caused by the $A$. brassicicola foliar pathogen on infected cabbage leaves. Disease incidence was significantly lower in the final evaluation period, with $\mathrm{Alt}+\mathrm{Sp}$ and Ssp+Alt at $18 \%$ and $26 \%$, respectively, and the control at $44 \%$. Moreover, disease infestation was also suppressed in nanoparticle-treated plants (Table 5).

Table 5. Disease incidence of $A$. brassicicola on cabbage leaves.

\begin{tabular}{ccccc}
\hline Treatment & Scale-9 DAI & Scale-12 DAI & Scale-15 DAI & $\begin{array}{c}\text { Disease } \\
\text { Incidence (\%) }\end{array}$ \\
\hline Alt & 2.57 & 2.57 & 3.14 & $44 \pm 5.96^{\mathrm{a}}$ \\
Alt+Sp & 1.42 & 1.28 & 1.14 & $18 \pm 2.43^{\mathrm{c}}$ \\
Alt+Np1 & 2.00 & 2.00 & 2.14 & $30 \pm 6.76^{\mathrm{b}}$ \\
Alt+Np2 & 1.28 & 1.57 & 2.28 & $32 \pm 6.55^{\mathrm{b}}$ \\
Ssp+Alt & 1.85 & 1.42 & 1.42 & $26 \pm 4.04^{\mathrm{bc}}$ \\
\hline
\end{tabular}

Alt-Alternaria brassicicola; $\mathrm{Sp}-$ Serendipita indica; $\mathrm{Np}$-nanoparticles; Ssp-seed application of S. indica; DAIdays after $A$. brassicicola inoculation. Mean values denoted by same letters does not show statistically significant difference. Means are followed by standard error data.

Development of disease incidence is seen in Table 4 as scaling in three terms. Control Alt treatment increased disease-affected areas by the last observation, while the opposite effect was recorded in $S$. indica treatments.

\subsection{Correlation}

A correlation was recorded in several treatments. In Alt treatment, chlorophyll $a$ and chlorophyll $b$ were positively correlated to TAC $(r=0.99)$. In Sp+Np1 and Alt+Np1, chlorophyll $a$ was positively correlated with $\mathrm{Ft}(r=0.99)$. In Ssp+Alt, chlorophyll $a$ showed a negative correlation with disease incidence $(r=-0.99)$, while chlorophyll $b$ showed a positive correlation with this parameter $(r=0.99)$.

\section{Discussion}

Beneficial microorganisms are being widely studied to avoid the indiscriminate use of chemical fertilizers and meet the increasing demand for healthy and chemical-free food production. Apart from this, environmental and economic security are considered major concerns [31]. Nanotechnology is also being used in crop production [32] as nanofertilizers, nanopesticides, and growth promoters $[33,34]$ to minimize the heavy application of fertilizers and improve the nutritional value of agricultural produce. Our research was based on applying the endophytic fungus, $S$. indica, and guanidine-modified nanomaterial on cabbage plants to study their effect on plant growth, development, and disease severity under greenhouse conditions. In this study, S. indica improved plant growth by enhancing the plants' morphological characters. Plant height was increased by $16 \%$ over control plants, and the number of leaves increased by $19 \%$ when $S$. indica application was introduced to the substrate compared to non-inoculated plants. However, in seed treatments, these effects were insignificant. Similar findings were reported by Trzewik et al. [35] that inoculation in substrate resulted in an increase in plant heights and numbers of leaves. The results also agree with Dolatabad et al., Bajaj et al., and Wang et al. [36-38], all reporting increased plant growth in $S$. indica-colonized plants. This morphological improvement could be due to better absorption of nutrients and water by $S$. indica-treated plants and the production of phytohormones, such as auxin and cytokinin [39-41]. The application of nanoparticles also improved plant growth compared to the control plants, similar to S. indica inoculation. The effect of guanidine-modified nanomaterial could be due to the increased uptake of water 
and nutrients in plants [42,43]. Growth-enhancing properties of graphene oxide were also reported by Park et al. [44].

S. indica and nanoparticle application showed a significant impact on the physiology of the plants, as both the NDVI and fluorescence were improved, mostly under substrate treatment. The NDVI showed an 11\% improvement in the combined application of S. indica and nanoparticles and an $8 \%$ increase in S. indica alone over controls. Even under Alternaria stress conditions, the NDVI was maintained in plants treated with the combination of $S$. indica and nanoparticles. This outcome could be attributed to the increase in the nitrogen assimilation by graphene oxide nanoparticles and increased uptake of nutrients, resulting in high green biomass that enhances the plants' physiological response under normal and stressed conditions. Chlorophyll fluorescence was reported higher in S. indica-inoculated plants in substrate treatment, potentially due to the increased chlorophyll content of funguscolonized plants. There was also a confirmed positive correlation between fluorescence and chlorophyll $a$ content in the treatment inoculated by $S$. indica. Many reports demonstrate the positive effect of $S$. indica on nitrogen content [45]. However, our experiment saw no improvement in nitrogen content when applying $S$. indica; similar results were obtained by Lin et al. and Achatz et al. $[8,46]$. Moreover, nitrogen content was recorded as higher in the plants treated with nanoparticles alone than in combination with S. indica. However, nitrogen content was improved under disease conditions in plants treated with fungus alone and even in the treatments combining S. indica and nanoparticles. This effect could be due to the improved performance of $S$. indica under stress conditions, resulting in the activation of NADH-dependent nitrate reductase (NR), the enzyme that plays a key role in nitrate acquisition in plants. Endophytic fungus $S$. indica and nanoparticles also increase the photosynthetic efficiency of plants by enhancing the photosynthetic pigments chlorophyll $a$ and $b$ content, resulting in increased plant growth. Treated plants also showed higher chlorophyll $a$ and $b$ under disease stress. Similar results were reported by [47-49]. Treatment with $S$. indica and guanidine-modified nanomaterial positively correlated to Ft values, showing that plants could perform better, even with low chlorophyll content, by increasing the fluorescence rate. In general, the experiment reported no synergically effective impact of combined application of S. indica and nanoparticles on seedlings, primarily in seed treatment. Total antioxidant capacity was not significantly affected by the application of $S$. indica and was insignificantly higher than the control. However, TAC was significantly improved in seed treatment by $S$. indica alone and combined application with nanoparticles. Moreover, under disease stress conditions, TAC was enhanced in plants treated with $S$. indica by $24 \%$ when applied in the root zone, possibly related to $S$. indica's defense response against the pathogen. Similar results were reported by [50]. An increase in TAC due to nanoparticles has been reported in various studies, suggesting that graphene oxide shows antipathogenic activity due to the activation of a signal cascade by the production of phytohormones such as jasmonic and shikimic acid [51]. Carotenoid content was enhanced by applying $S$. indica and nanoparticles under disease conditions, except for Alt+Np2 treatment. Similar results were reported in other works [52-54]. An increase in carotenoid content by nanoparticles was confirmed in [48]. A correlation was reported between antioxidant capacity, chlorophyll $a$, and chlorophyll $b$ in Alternaria treatment, showing a reducing trend within these parameters and confirming the negative effect of Alternaria infestation on plants.

Our experiment reported that under biotic stress conditions, $S$. indica, and to some extent, nanoparticles, can maintain and improve plant growth. Fewer disease symptoms were seen in the plants treated with $S$. indica alone in substrate application, where it reduced the infection incidence by $59 \%$ in treated plants compared to the controls and by $49 \%$ in seed treatment. Roylawar et al. [55] demonstrate the biocontrol potential of S. indica against Stemphylium leaf blight in onions. The beneficial effect of the fungus could be due to the activation of antioxidative enzymes and the expression of defense or pathogen-related genes [5]. In our experiment, the increase in antioxidant capacity in plants treated with $S$. indica under disease conditions could be related to reducing the disease severity of 
pathogen-treated plants. Thus, the results show that $S$. indica could potentially be used as a biocontrol agent against $A$. brassicicola. Similar results were reported by $[8,56,57]$.

Contrary to the control, nanoparticles showed disease limitation from $27 \%$ to $32 \%$. This result could be attributed to enhancing the antioxidant defense mechanism by activating antioxidant enzymes. Ganjavi et al. [58] reported an improvement in superoxide dismutase, ascorbate peroxidase, and glutathione reductase by foliar application of graphene oxide. Apart from producing antioxidants, graphene oxide can directly prevent pathogen attacks by interacting with microorganisms and masking the active sites due to its lamellar structure. Furthermore, it can hinder the activity of microorganisms by covering their surfaces and reducing their growth [59]. Similar results were confirmed in previous research $[48,49,60]$. This investigation shows that treatment with the beneficial microorganism $S$. indica effectively reduces disease incidence caused by $A$. brassicicola.

\section{Conclusion}

This investigation's findings supported using $S$. indica as a growth-promoting organism under greenhouse conditions when applied in the root zone. However, seed treatment biochemical parameters reported better performance. Guanidine-modified nanomaterials based on graphene oxide were also reported as beneficial, but did not surpass the performance of $S$. indica endophytic fungus application. The study of beneficial fungus $S$. indica on cabbage positively influenced many observed plant parameters. Moreover, one of the important results derived from the investigation was using $S$. indica as a biocontrol agent. The findings support the increased performance of $S$. indica in improving plants biochemical properties and nutrient uptake under biotic stress. Thus, the study confirms the potential of $S$. indica to be used as a remedy against pathogen attacks under greenhouse conditions.

Analyzing the economic issues of $S$. indica would be interesting for further research, as cultivation of this fungus does not require costly equipment or chemicals. Therefore, production costs could be low and comparable to the commercially used mycorrhizal inoculation available in the market. The key economic benefit of nanomaterials in agriculture is their substantially lower needs, by several orders of magnitude, with the same effects as bulk material. In this study, graphene oxide is the substance carrier, ensuring persistence, long-term effects, and less active substance requirements. However, the exploitation of guanidine nanomaterials has undergone upscaling, so estimating the cost of this application is challenging. However, our university can produce relatively high amounts for on-site practical tests.

Author Contributions: Conceptualization, L.R. and R.P.; methodology, Z.B. and R.P.; software, R.P.; validation, R.P., Z.B. and L.R.; formal analysis, R.P.; investigation, S.S. and R.P.; resources, Z.B., R.P. and L.R.; data curation, S.S. and Z.B.; writing-original draft preparation, S.S.; writing-review and editing, S.S., R.P., Z.B. and L.R.; visualization, R.P. and S.S.; supervision, R.P. and L.R.; project administration, R.P.; funding acquisition, R.P. All authors have read and agreed to the published version of the manuscript.

Funding: Supported by the project of the Internal Grant Agency of Mendel University in Brno (no. IGA-ZF/2021-SI1004) "Cultivation techniques and inoculation of vegetables by symbiotic microbes". Microscopic analyses were carried out on infrastructure supported by project OP VVV CZ.02.1.01/0.0/0.0/16_017/0002334. Research infrastructure for young scientists, financed from structural funds of EU and Ministry of Education of the Czech Republic.

Institutional Review Board Statement: Not applicable.

Informed Consent Statement: Not applicable.

Data Availability Statement: All relevant data are contained within the manuscript.

Acknowledgments: The authors are thankful to Lucia Ragasová for providing help in cultivation of S. indica. The authors would also like to acknowledge Pavel Švec for his expertise in the field of electron microscopy and assistance with performing measurements. 
Conflicts of Interest: The authors declare no conflict of interest.

\section{References}

1. Cho, Y. How the necrotrophic fungus Alternaria brassicicola kills plant cells remains an enigma. Eukaryot. Cell. 2015, 14, 335-344. [CrossRef] [PubMed]

2. Manha, R.K.; Kaur, T. Biocontrol Potential of Streptomyces hydrogenans Strain DH16 toward Alternaria brassicicola to Control Damping Off and Black Leaf Spot of Raphanus sativus. Front. Plant Sci. 2016, 7, 1869. [CrossRef]

3. Macioszek, V.K.; Gapińska, M.; Zmienko, A.; Sobczak, M.; Skoczowski, A.; Oliwa, J.; Kononowicz, A.K. Complexity of Brassica oleracea-Alternaria brassicicola Susceptible Interaction Reveals Downregulation of Photosynthesis at Ultrastructural, Transcriptional, and Physiological Levels. Cells 2020, 9, 2329. [CrossRef] [PubMed]

4. Mahanty, T.; Bhattacharjee, S.; Goswami, M.; Bhattacharyya, P.; Das, B.; Ghosh, A.; Tribedi, P. Biofertilizers: A potential approach for sustainable agriculture development. Environ. Sci. Pollut. Res. 2017, 24, 3315-3335. [CrossRef] [PubMed]

5. Bajaj, R.; Huang, Y.; Gebrechristos, S.; Mikolajczyk, B.; Brown, H.; Prasad, R.; Varma, A.; Bushley, K.E. Transcriptional responses of soybean roots to colonization with the root endophytic fungus Piriformospora indica reveals altered phenylpropanoid and secondary metabolism. Sci. Rep. 2018, 8, 1-18. [CrossRef]

6. Meena, M.; Swapnil, P.; Zehra, A.; Aamir, M.; Dubey, M.K.; Goutam, J.; Upadhyay, R. Beneficial microbes for disease suppression and plant growth promotion. In Plant-Microbe Interactions in Agro-Ecological Perspectives; Springer: Springer, 2017; pp. 395-432. [CrossRef]

7. Gill, S.S.; Gill, R.; Trivedi, D.K.; Anjum, N.A.; Sharma, K.K.; Ansari, M.W.; Tuteja, N. Piriformospora indica: Potential and significance in plant stress tolerance. Front. Microbiol. 2016, 7, 332. [CrossRef] [PubMed]

8. Lin, H.F.; Xiong, J.; Zhou, H.M.; Chen, C.M.; Lin, F.Z.; Xu, X.M.; Oelmuller, R.; Xu, W.F.; Yeh, K.W. Growth promotion and disease resistance induced in Anthurium colonized by the beneficial root endophyte Piriformospora indica. BMC Plant Biol. 2019, 19, 1-10. [CrossRef]

9. Verma, S.; Varma, A.; Rexer, K.; Hassel, A.; Kost, G.; Sarbhoy, A.; Franken, P. Piriformospora indica, gen. et sp. nov., a New Root-Colonizing Fungus. Mycologia 1998, 90, 896-903. [CrossRef]

10. Fakhro, A.; Andrade-Linares, D.R.; Von, B.S.; Bandte, M.; Büttner, C.; Grosch, R.; Schwarz, D.; Franken, P. Impact of Piriformospora indica on tomato growth and on interaction with fungal and viral pathogens. Mycorrhiza 2010, 20, 191-200. [CrossRef]

11. Khalid, M.; Hui, N.; Rahman, S.U.; Hayat, K.; Huang, D. Suppression of clubroot (Plasmodiophora brassicae) development in Brassica campestris sp. chinensis L. via exogenous inoculation of Piriformospora indica. J. Radiat. Res. Appl. Sci. 2020, 13, 180-190. [CrossRef]

12. Finkel, O.M.; Castrillo, G.; Herrera Paredes, S.; Salas Gonzalez, I.; Dangl, J.L. Understanding and exploiting plant beneficial microbes. Curr. Opin. Plant Biol. 2017, 38, 155-163. [CrossRef]

13. Wang, Y.; Lin, Y.; Xu, Y.; Yin, Y.; Guo, H.; Du, W. Divergence in response of lettuce (var. ramosa Hort.) to copper oxide nanoparticles/microparticles as potential agricultural fertilizer. Environ. Pollut. Bioavailab. 2019, 31, 80-84. [CrossRef]

14. Kole, C.; Kole, P.; Randunu, K.M.; Choudhary, P.; Podila, R.; Ke, P.C.; Rao, A.M.; Marcus, R.K. Nanobiotechnology can boost crop production and quality: First evidence from increased plant biomass, fruit yield and phytomedicine content in bitter melon (Momordica charantia). BMC Biotechnol. 2013, 13, 37. [CrossRef]

15. Shalaby, T.A.; Bayoumi, Y.; Abdalla, N.; Taha, H.; Alshaal, T.; Shehata, S.; Amer, M.; Domokos-Szabolcsy, É.; El-Ramady, H. Nanoparticles, soils, plants, and sustainable agriculture. In Nanoscience in Food and Agriculture 1; Shivendu, R., Nandita, D., Eric, L., Eds.; Springer: Cham, Switzerland, 2016; pp. 283-312.

16. Sabir, A.; Yazar, K.; Sabir, F.; Kara, Z.; Yazici, M.A.; Goksu, N. Vine growth, yield, berry quality attributes and leaf nutrient content of grapevines as influenced by seaweed extract (Ascophyllum nodosum) and nanosize fertilizer pulverizations. Sci. Hortic. 2014, 175, 1-8. [CrossRef]

17. Zand, A.D.; Tabrizi, A.M.; Heir, A.V. Co-application of biochar and titanium dioxide nanoparticles to promote remediation of antimony from soil by Sorghum bicolor: Metal uptake and plant response. Heliyon. 2020, 6, e04669. [CrossRef]

18. Sardar, R.; Ahmed, S.; Yasin, N.A. Titanium dioxide nanoparticles mitigate cadmium toxicity in Coriandrum sativum through modulating antioxidant system, stress markers and reducing cadmium uptake. Environ. Pollut. 2022, 292, 118373. [CrossRef] [PubMed]

19. Manjaiah, K.M.; Mukhopadhyay, R.; Paul, R.; Datta, S.C.; Kumararaja, P.; Sarkar, B. Clay minerals and zeolites for environmentally sustainable agriculture. Mariano, M., Binoy, S., Alessio, L., Eds.; Elsevier: Amsterdam, The Netherlands, 2019; pp. 309-329. [CrossRef]

20. Ponce-García, C.O.; Soto-Parra, J.M.; Sánchez, E.; Muñoz-Márquez, E.; Piña-Ramírez, F.J.; Flores-Córdova, M.A.; Pérez-Leal, R.; Yáñez Muñoz, R.M. Efficiency of nanoparticle, Sulfate, and Zinc-Chelate Use on Biomass, Yield, and Nitrogen Assimilation in Green Beans. Agronomy 2019, 9, 128. [CrossRef]

21. Mishra, S.; Singh, H.B. Biosynthesized silver nanoparticles as a nanoweapon against phytopathogens: Exploring their scope and potential in agriculture. Appl. Microbiol. Biotechnol. 2015, 99, 1097-1107. [CrossRef] [PubMed]

22. Jurkow, R.; Pokluda, R.; Sękara, A. Impact of foliar application of some metal nanoparticles on antioxidant system in oakleaf lettuce seedlings. BMC Plant Biol. 2020, 20, 290. [CrossRef] 
23. Zhang, Z.; Nyborg, M.; Worsley, M.; Worsley, K.M.; Gower, D.A. Guanidine sulphate: Slow release of mineral nitrogen during incubation in soil. Commun Soil Sci. Plant Anal. 1992, 23, 431-439. [CrossRef]

24. Varma, A.; Uma, K.M. Role of Nanoparticles on Plant Growth with Special Emphasis on Piriformospora indica: A Review. In Nanoscience and Plant-Soil Systems; Soil Biology; Ghorbanpour, M., Manika, K., Varma, A., Eds.; Springer: Cham, Switzerland, 2017; Volume 48, pp. 387-403. [CrossRef]

25. Richtera, L.; Chudobova, D.; Cihalova, K.; Kremplova, M.; Milosavljevic, V.; Kopel, P.; Blazkova, I.; Hynek, D.; Adam, V.; Kizek, R. The Composites of Graphene Oxide with Metal or Semimetal Nanoparticles and Their Effect on Pathogenic Microorganisms. Materials 2015, 8, 2994-3011. [CrossRef]

26. Holm, G. Chlorophyll mutations in barley. Acta Agric. Scand. 1954, 4, 457-471. [CrossRef]

27. Brand-Williams, W.; Cuvelier, M.E.; Berset, C.L.W.T. Use of a free radical method to evaluate antioxidant activity. LWT-Food Sci Technol. 1995, 28, 25-30. [CrossRef]

28. Zbíral, J. Analýza Rostlinného Materiálu: Jednotné Pracovní Postupy; Vyd. 2; UKZUZ: Brno, Czech Republic, 2005. (In Czech)

29. Nowakowska, M.; Wrzesińska, M.; Kamiński, P.; Szczechura, W.; Lichocka, M.; Tartanus, M.; Kozik, E.U.; Nowicki, M. Alternaria brassicicola-Brassicaceae pathosystem: Insights into the infection process and resistance mechanisms under optimized artificial bio-assay. Eur. J. Plant Pathol. 2019, 153, 131-151. [CrossRef]

30. Sabry, S.; Ali, A.Z.; Dawlat, A.; Abdel, K.; Abou-Zaid, A.I. Control of cabbage Alternaria leaf spot disease caused by Alternaria brassicicola. Zagazig J. Agric. Res. 2015, 42.

31. Singh, J.S.; Pandey, V.C.; Singh, D.P. Efficient soil microorganisms: A new dimension for sustainable agriculture and environmental development. Agr. Ecosyst. Environ. 2011, 140, 339-353. [CrossRef]

32. Sekhon, B.S. Nanotechnology in agri-food production: An overview. Nanotechnol. Sci. Appl. 2014, 7, 31-53. [CrossRef] [PubMed]

33. Fraceto, L.F.; Grillo, R.; de Medeiros, G.A.; Scognamiglio, V.; Rea, G.; Bartolucci, C. Nanotechnology in agriculture: Which innovation potential does it have? Front. Environ. Sci. 2016, 4, 20. [CrossRef]

34. Wang, S.; Wang, F.; Gao, S.; Wang, X. Heavy metal accumulation in different rice cultivars as influenced by foliar application of nano-silicon. Water Air Soil Pollut. 2016, 7, 1-13. [CrossRef]

35. Trzewik, A.; Orlikowska, T.; Kowalczyk, W.; Maciorowski, R.; Ciołakowska-Marasek, A.; Klocke, E. Stimulation of ex vitro growth of Rhododendron hybrids 'Nova Zembla' and 'Alfred' by inoculation of roots with Piriformospora indica. Hort. Sci. 2020, 47, 194-202. [CrossRef]

36. Dolatabadi, H.K.; Goltapeh, E.M. Effect of inoculation with Piriformospora indica and Sebacina vermifera on growth of selected Brassicaceae plants under greenhouse conditions. Hortic Res. 2013, 21, 115-124. [CrossRef]

37. Bajaj, R.; Hu, W.; Huang, Y.Y.; Prasad, R.; Varma, A.; Bushley, K.E. The beneficial root endophyte Piriformospora indica reduces egg density of the soybean cyst nematode. Biol. Control 2015, 90, 193-199. [CrossRef]

38. Wang, H.; Zheng, J.; Ren, X.; Yu, T.; Varma, A.; Lou, B.; Zheng, X. Effects of Piriformospora indica on the growth, fruit quality and interaction with Tomato yellow leaf curl virus in tomato cultivars susceptible and resistant to TYCLV. Plant Growth Regul. 2015, 76, 303-313. [CrossRef]

39. Singh, A.; Sharma, J.; Rexer, K.H.; Varma, A. Plant productivity determinants beyond minerals, water and light: Piriformospora indica-A revolutionary plant growth promoting fungus. Curr. Sci. 2000, 79, 1548-1554.

40. Varma, A.; Singh, A.; Sahay, N.S.; Sharma, J.; Roy, A.; Kumari, M. Piriformospora indica: An axenically culturable mycorrhiza-like endosymbiotic fungus. In Fungal Associations; Springer: Heidelberg, Berlin, 2001; Volume 9. [CrossRef]

41. Vadassery, J.; Ranf, S.; Drzewiecki, C.; Mithöfer, A.; Mazars, C.; Scheel, D.; Lee, J.; Oelmüller, R. A cell wall extract from the endophytic fungus Piriformospora indica promotes growth of Arabidopsis seedlings and induces intracellular calcium elevation in roots. Plant J. 2009, 59, 193-206. [CrossRef]

42. Tripathi, S.; Sonkar, S.K.; Sarkar, S. Growth stimulation of gram (Cicer arietinum) plant by water soluble carbon nanotubes. Nanoscale 2011, 3, 1176-1181. [CrossRef]

43. Martínez-Ballesta, M.C.; Zapata, L.; Chalbi, N.; Carvajal, M. Multiwalled carbon nanotubes enter broccoli cells enhancing growth and water uptake of plants exposed to salinity. J. Nanobiotechn. 2016, 14, 1-14. [CrossRef]

44. Park, S.; Choi, K.S.; Kim, S.; Gwon, Y.; Kim, J. Graphene oxide-assisted promotion of plant growth and stability. Nanomaterials 2020, 10, 758. [CrossRef]

45. Sherameti, I.; Shahollari, B.; Venus, Y.; Altschmied, L.; Varma, A.; Oelmüller, R. The endophytic fungus Piriformospora indica stimulates the expression of nitrate reductase and the starch-degrading enzyme glucan-water dikinase in tobacco and Arabidopsis roots through a homeodomain transcription factor that binds to a conserved motif in their promoters. J. Biol. Chem. 2005, 280, 26241-26247. [CrossRef] [PubMed]

46. Achatz, B.; Van Rüden, S.; Andrade, D.; Neumann, E.; Pons Kühnemann, J.; Kogel, K.H.; Franken, P.; Waller, F. Root colonization by Piriformospora indica enhances grain yield in barley under diverse nutrient regimes by accelerating plant development. Plant Soil. 2010, 333, 57-59. [CrossRef]

47. Shahabivand, S.; Alíloo, A.A. Piriformospora indica promotes growth and antioxidant activities of wheat plant under cadmium stress. Yüzüncü Yil Üniv. J. Agric. 2016, 26, 333-340.

48. Siddiqui, Z.A.; Parveen, A.; Ahmad, L.; Hashem, A. Effects of graphene oxide and zinc oxide nanoparticles on growth, chlorophyll, carotenoids, proline contents and diseases of carrot. Sci. Hortic. 2019, 249, 374-382. [CrossRef] 
49. González-García, Y.; Cadenas-Pliego, G.; Alpuche-Solís, A.G.; Cabrera, R.I.; Juárez-Maldonado, A. Effect of carbon-based nanomaterials on Fusarium wilt in tomato. Sci. Hortic. 2022, 291, 110586. [CrossRef]

50. Prasad, R.; Kamal, S.; Sharma, P.K.; Oelmüller, R.; Varma, A. Root endophyte Piriformospora indica DSM 11827 alters plant morphology, enhances biomass and antioxidant activity of medicinal plant Bacopa monniera. J. Basic Microbiol. 2013, 53, 1016-1024. [CrossRef] [PubMed]

51. Jordan, J.T.; Singh, K.P.; Cañas-Carrell, J.E. Carbon-based nanomaterials elicit changes in physiology, gene expression, and epigenetics in exposed plants: A review. Curr. Opin. Environ. Sci. Health. 2018, 6, 29-35. [CrossRef]

52. Baishya, D.; Deka, P.; Kalita, M.C. In vitro co-cultivation of Piriformospora indica filtrate for improve biomass productivity in Artemisia annua (L.). Symbiosis 2015, 66, 37-46. [CrossRef]

53. Abadi, V.A.J.M.; Sepehri, M. Effect of Piriformospora indica and Azotobacter chroococcum on mitigation of zinc deficiency stress in wheat (Triticum aestivum L.). Symbiosis 2016, 69, 9-19. [CrossRef]

54. Khalid, M.; Hassani, D.; Bilal, M.; Liao, J.; Huang, D. Elevation of secondary metabolites synthesis in Brassica campestris ssp. chinensis L. via exogenous inoculation of Piriformospora indica with appropriate fertilizer. PLoS ONE 2017, 12, e0177185. [CrossRef]

55. Roylawar, P.; Khandagale, K.; Randive, P.; Shinde, B.; Murumkar, C.; Ade, A.; Singh, M.; Gawande, S.; Morelli, M. Piriformospora indica Primes Onion Response against Stemphylium Leaf Blight Disease. Pathogens 2021, 10, 1085. [CrossRef] [PubMed]

56. Stein, E.; Molitor, A.; Kogel, K.H.; Waller, F. Systemic resistance in Arabidopsis conferred by the mycorrhizal fungus Piriformospora indica requires jasmonic acid signalling and the cytoplasmic function of NPR1. Plant Cell Physiol. 2008, 49, 1747-1751. [CrossRef]

57. del Barrio-Duque, A.; Ley, J.; Samad, A.; Antonielli, L.; Sessitsch, A.; Compant, S. Beneficial endophytic bacteria-Serendipita indica interaction for crop enhancement and resistance to phytopathogens. Front. Microbiol. 2019, 10, 2888. [CrossRef] [PubMed]

58. Ganjavi, A.S.; Oraei, M.; Gohari, G.; Akbari, A.; Faramarzi, A. Glycine betaine functionalized graphene oxide as a new engineering nanoparticle lessens salt stress impacts in sweet basil (Ocimum basilicum L.). Plant Physiol. Biochem. 2021, 162, 14-26. [CrossRef] [PubMed]

59. Ji, H.; Sun, H.; Qu, X. Antibacterial applications of graphene-based nanomaterials: Recent achievements and challenges. Adv. Drug Deliv. Rev. 2016, 105, 176-189. [CrossRef] [PubMed]

60. Wang, X.; Liu, X.; Chen, J.; Han, H.; Yuan, Z. Evaluation and mechanism of antifungal effects of carbon nanomaterials in controlling plant fungal pathogen. Carbon 2014, 68, 798-806. [CrossRef] 